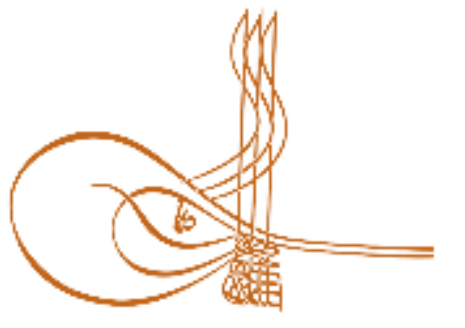

www.turkishstudies.net/turkishstudies
Turkish Studies

eISSN: $1308-2140$

Research Article / Araştırma Makalesi

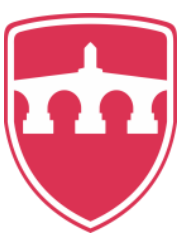

INTERNATIONAL

BALKAN

UNIVERSITY

Sponsored by IBU

\title{
Türk Kadınının Giyinme Kültüründeki Değişimde Kadın Dergilerinin Etkisi: II. Meşrutiyet Dönemi Mehasin Dergisi Örneğï
}

\author{
The Effect Of Women's Magazınes In Change Of Turkish Women's Clothing Culture: Example Of \\ Mehasin Magazıne II. Meşrutiyet Period
}

\author{
Emine Koca** ${ }^{*}$ Gülşah Polat***
}

\begin{abstract}
During 2nd Mesrutiyet period, the Ottoman state started to follow Europe in many areas and went to innovations within its own body. One of the most remarkable features of this period was the freedoms given to the Ottoman woman. It can be clearly seen in the magazines of the period that the media played an important role in the changes and developments in the education, work and social life of women. With the developing thought flows and press activities, magazines for women have come to the fore and women's development has been supported in a wide range from housework, child care, literature to fashion. In addition to clothing, personal care and women's magazines, women's magazines gave importance to the concept of fashion and presented informative information to women in almost every issue along with fashion-oriented images. 2nd Mesrutiyet Being one of the important women's magazines of the constitutional era, Mehasin magazine was one of the first magazines that contributed to the development of Turkish women in every field, especially with its fashion-oriented pages, it was effective in the adoption of Western clothing style and the spread of fashion. In this study, it is aimed to determine the qualitative (design) features of women's fashion in Mehasin magazine and to interpret the effects of Turkish women on the change of dressing culture; Using the content analysis method, the fashion visuals in the issues of the magazine published between 1906-1907 were grouped in chronological order. During the review process, thematic coding was done and formal drawings of the clothing images were made according to the codes, and themes were created. In line with the information obtained from the Turkish translation of the Ottoman texts on the pages, the design features of the European women's fashion of the period were interpreted. As a result of the research, the code and theme scheme of the visuals reflecting the European women's clothing fashion in Mehasin Magazines between 1906-1907 were created. In the emerging themes, it was observed that Mehasin magazine mostly included information and visuals for
\end{abstract}

\footnotetext{
* Bu makale doktora tezinin ön çalışmasının bir bölümünden üretilmiştir.

** Prof. Dr., Ankara Hacı Bayram Veli Üniversitesi, Sanat ve Tasarım Fakültesi, Moda Tasarımı Bölümü

Prof. Dr. Ankara Hacı Bayram Veli University Faculty of Arts and Design, Department of Fashion Design

ORCID 0000-0001-6607-5652

kocaemine@gmail.com

**** Öğr. Gör., Giresun Üniversitesi Şebinkarahisar Uygulamalı Bilimler Yüksekokulu

Lect., Giresun University, Şebinkarahisar Academy of Applied Sciences

ORCID 0000-0001-8448-9947

gpolat011990@hotmail.com

Cite as/ Atıf: Koca, E. Polat, G. (2020). Türk kadınının giyinme kültüründeki değişimde kadın dergilerinin etkisi: II.

Meşrutiyet Dönemi Mehasin Dergisi örneği, Turkish Studies, 15(1), 429-445

https://dx.doi.org/10.29228/TurkishStudies.39862

Received/Geliş: 21 November/Kasım 2019

Accepted/Kabul: 25 February/Şubat 2020

Copyright $\mathbb{C}$ MDE, Turkey

Checked by plagiarism software

Published/Yayın: 29 February/Şubat 2020

CC BY-NC 4.0
} 
European women and clothing fashion. It is thought that this study will be a source for Turkish clothing history and will contribute to our cultural accumulation.

Structured Abstract: Introduction Many women's magazines published during 2nd Meşrutiyet period covered many issues related to women's self-development, but they took care to include Western fashion in almost every issue in the context of clothing and decoration. Women's magazines, which have been published by women in the long and short term, have become an important tool that directs women's clothing styles. Therefore, the visibility of women in social life became more pronounced with the change of clothing style and prepared the ground for further discussions. The main subject of the discussions was the fact that the Turkish women's clothing, which has great cultural importance with its unchanging features for many years, began to shift towards European clothing styles in this period.

This change, which is perceived as a detachment from traditional and cultural values, has been seen by some thinkers, writers and groups as an important problem in cultural, national and religious terms. While some support Europe in women's fashion, some have argued that religious provisions must be followed and that women should not be taken out of traditions in the face of nasty imitations, while others emphasize the importance of national values and that there must be a national costume. Despite all the controversies, the European change in women's clothing, the effect of which was initially seen in Istanbul, was inevitably reflected in other cities over time. The change in women's clothing was seen not only formally, but also in materials, ornaments and accessories.

The Turkish women's liberation and modernization started an important process in the Women's magazines in 2nd Meşrutiyet period, with their fashion-oriented content, led to changes in women's clothing styles, giving the Meşrutiyet a new image. Considering that this image constitutes the first steps of modern clothing style of today's Turkish woman, it reveals that visual and information about women's fashion in magazines of the period is important for examining the change process of Turkish women's clothing style and forms the starting point of this study. In this study, The qualitative (design) characteristics of women's fashion in the issues of Mehasin, one of the women's magazines published in 2nd Meşrutiyet period, published between 1906-1907, were aimed to be interpreted and reflected on the reflections of Turkish women on dressing culture change. Due to the fact that Mehasin magazine included more women's fashion than other women's magazines published in the period, the general characteristics of European women's fashion of the period were examined and explained. The research contributes to the accumulation of knowledge from the primary source and is important in terms of creating a source for the history of Turkish clothing.

\section{LiteratureReview}

In this period, the enrichment in publication life and the accompanying women's and magazines focused on the status and status of women in society played an important role. Among the issues that make up the agenda is that women's rights-seeking efforts in the press have altered men's perspectives and in this way men have discussed women. In the women's magazine Mehasin, which is one of the magazines published after the declaration of 2nd Meşrutiyet period, stated that men reflected their ideas of freedom to their home sand women started to get rid of traditional ideas by beingin fluenced by the ideas (Asaf, 1324: 2-3). Her introduced all aspects of European women, which emerged under the influence of Western thought in the environment of freedom created by 2nd Meşrutiyet period (Koca, 2012: 678).

\section{Method}

The content analysis method was used in this qualitative research, which aimed to interpret the effects of Turkish women on the change of dressing culture by determining the qualitative (design) characteristics of women's fashion in the issues of Mehasin magazine, one of the women's magazines of 2nd Meşrutiyet period, published between 1906-1907. In order to reach the aim of the research, the following questions were searched in line with the codes and themes they created:

- What are the silhouette, sleeve and collar characteristics of women's clothing on the pages of European fashion in Mehasin magazine?

- What are the decoration and accessory features of women's clothing on the pages of European fashion in Mehasin magazine? 
- What are the material / fabric characteristics of women's clothing on the pages of European fashion in Mehasin magazine?

In this research, fashionable pages of Mehasin magazine published between the years 1906-190712 were identified, visuals with fully visible garment characteristics were determined, visuals were created in chronological order and visually examined by content analysis method. The visuals that best reflect all the characteristics of similar clothing visuals were included in the research. Thematic coding process was carried out during the examination process, formal drawings of clothes images were made according to the codes and themes were created. In line with the information obtained from the Turkish translation of the Ottoman texts on the pages, the design features of the European women's fashion of the period were explained and their reflections on the dressing culture of Turkish women were interpreted. In addition, the code and theme scheme of the visuals reflecting the European women's wear fashion of the period was drawn and the framework of the women's wear fashion was drawn.

\section{Findings and Discussion}

In order to determine the qualitative (design) characteristics of women's clothing fashion published in Mehasin magazine published between the years of 1906-1907 during 2nd Meşrutiyet period, the thematic coding in which chronologically listed magazine images were individually coded under silhouette, sleeve, collar and ornament headings and common themes were formed. Tables are presented below. Since the visuals in the magazines are black and white, the fabric and material properties of the garments cannot be examined clearly, so these codes and themes are not included in the tables. Although the contents of the magazine's pages for women's fashion vary in every issue, they contain information that enlightens Turkish women about garment supplements, ornamentation and especially hair care.

\section{Conclusion}

In this research, it was aimed to determine the qualitative (design) characteristics of women fashion in the issues of Mehasin magazine, which is one of the women's magazines in the period of 2nd Meşrutiyet period, published between 1906-1907 and to interpret the effects of Turkish women on the change of dressing culture. In all of the issues of Mehasin magazine, fashion clothing style and the image of European women were reflected and it was seen that pattern, sewing, ornament and hair- beauty issues that complement this style were given almost the same ratio. As a result of examining the clothes visuals in the fashion pages where mainly French fashion is predominant with thematic coding tables; The codes of women's fashion of the period and their themes are presented in the form.

Keywords: Ottoman, 2nd Meşrutiyet, magazine, women, fashion, dressing culture

Öz: II. Meşrutiyet döneminde Osmanlı devleti birçok alanda Avrupa'yı takip etmeye başlamış ve kendi bünyesinde yenliklere gitmiştir. Bu dönemin en dikkat çekici özelliklerinden biri de Osmanlı kadınına tanınan özgürlükler olmuştur. Kadının eğitim, çalışma ve sosyal yaşamındaki değişim ve gelişmelerde basının önemli rolü olduğu, döneme ait dergilerde açıkça görülebilmektedir. Gelişen düşünce akımları ve basın faaliyetleriyle birlikte kadına yönelik dergiler ön plana çıkmış, ev işlerinden, çocuk bakımına, edebiyattan, modaya kadar geniş bir yelpazede kadının gelişimi desteklenmiştir. Kadın dergileri, giyim kuşam ve kişisel bakımın yanı sıra moda olgusuna önem vermiş ve hemen hemen her sayısında modaya yönelik görsellerle birlikte yönlendirici bilgileri kadınlara sunmuştur. II. Meşrutiyet döneminin önemli kadın dergileri arasında yer alan Mehasin dergisi Türk kadınının her alanda gelişimine katkıda bulunan ilk dergilerden biri olarak, özellikle modaya yönelik sayfalarıyla batılı giyim tarzının benimsenmesinde ve modanın yaygınlaşmasında etkili olmuştur. Mehasin dergisindeki kadın modasının nitel (tasarım) özelliklerinin belirlenerek, Türk kadınının giyinme kültürünün değişimine etkilerinin yorumlanmasının amaçlandığı bu çalışmada; içerik analizi yöntemi kullanılarak derginin 1906-1907 yılları arasında yayınlanan sayılarındaki modaya yönelik görseller kronolojik olarak tablolarda gruplandırılmıştır. İnceleme sürecinde tematik kodlama işlemi yapılarak, kodlara göre giysi görsellerinin biçimsel çizimleri yapılmış ve temalar oluşturulmuştur. Sayfalardaki Osmanlıca metinlerin Türkçe çevirisinden elde edilen bilgiler doğrultusunda dönemin Avrupa kadın modasının tasarım özellikleri yorumlanmıştır. Araştırma sonucunda, 1906-1907 yılları Mehasin Dergilerindeki Avrupa kadın giyim modasını yansıtan görsellerin kod ve tema şeması oluşturulmuştur. Ortaya çıkan temalarda, Mehasin dergisinin çoğunlukla Avrupalı kadın ve giyim modasına yönelik bilgi ve görsellere yer verdiği görülmüştür. Bu 
çalışmanın Türk giyim tarihine kaynak oluşturacağı ve özellikle kültürel birikimimize katkı sağlayacağı düşünülmektedir.

Anahtar Kelimeler: Osmanlı, II. Meşrutiyet, dergi, kadın, moda, giyinme kültürü

\section{Giriş}

1908 yılında ilan edilen II. Meşrutiyet ile başlayan yenileşme hareketleri ilk başlarda siyasi, eğitim, hukuk gibi alanlarda uygulanırken, değişim ve dönüşümün dinamikleri kadınlara da yansımış, daha önceleri hiç görülmemiş bir kadın hareketinin biçimlenmesini de sağlamıştır. Kadınların bu yıllarda, bilinen kadın profilinden çok farklı bir biçimde, hak talep eden mücadeleci tavırlarıyla basında, eğitimde, sanatta ve çalışma hayatında etkilerini artırarak, düşünebilen ve eleştirebilen bir birey olarak kendilerini ifade etmeye başlamasıyla, erkeklerin gözünde de kadının konumu değişmiş̧ir. Akgündüz (2013:64) bu değişimi; İttihat ve Terakki Fırkası'nın düşünsel ve toplumsal kurgulaması kadınları farklılaştırmış, aydınlanmış Osmanlı erkeklerinin gözünde kadın, modernleşmenin aracı olarak algılanmıştır şeklinde açıklamaktadır. Bu dönemde yayın hayatındaki zenginleşme ve beraberinde ortaya çıkan kadının toplumdaki yeri ve statüsü üzerine odaklanmış olan kadın ve düşünce dergilerinin önemli rolü olmuştur. Basında yer alan kadınların hak arama çabalarının erkeklerin de bakış açılarını değiştirdiği, bu sayede erkeklerin kadınları tartışır olduğu, gündemi oluşturan konular arasında yer almıştır. Meşrutiyet'in ilanından sonra yayınlanan dergilerden biri olan kadın dergisi Mehasin'de Asaf Muammer (1324: 2-3), erkeklerin özgürlük düşüncelerini evlerine yansıttıkları, kadınların ise bu düşüncelerden etkilenerek, geleneksel anlayışlardan kurtulmaya başladıklarını belirtmiştir.

II. Meşrutiyet döneminde yayınlanan çok sayıda kadın dergisi, kadınların kendilerini geliştirmelerine yönelik pek çok konuyu ele almakla birlikte, giyim kuşam ve süslenme bağlamında Batı modasına hemen hemen her sayısında yer vermeye özen göstermiştir. Özellikle kadınlar tarafından yayınlanmaya başlayan, uzun ve kısa dönemli basılan kadın dergileri, kadınların giyim tarzlarını yönlendiren önemli bir araç olmuştur. Dolayısıyla kadınların toplumsal yaşamda görünürlüğü giyim tarzının değişime uğramasıyla daha belirgin hale gelerek, başka tartışmalara da zemin hazırlamıştır. Uzun yıllar değişmezlik gösteren özellikleriyle kültürel açıdan büyük öneme sahip olan Türk kadını giyim kuşamının bu dönemde değişim göstererek, kadınların Avrupai giyim tarzlarına yönelmeye başlaması, tartışmaların ana konusu olmuştur. Geleneksel ve kültürel değerlerden kopuş olarak algılanan bu değişim, bazı düşünürler, yazarlar ve gruplar tarafından kültürel, milli ve dini açıdan önemli bir sorun olarak görülmüştür. Bazıları kadın modasında Avrupa'yı desteklerken, bazıları dini hükümlere uyulması gerektiğini ve batıcı taklitçiliğin karşısında kadını geleneklerin dışına çıkartmamayı, bazıları ise milli değerlerin önemine vurgu yaparak milli kılık-kıyafetin olması gerektiğini savunmuştur. Bütün tartışmalara rağmen, başlangıçta etkisi İstanbul da görülen kadın giyimindeki Avrupai değişimin, zamanla diğer şehirlere de yansıması kaçınılmaz olmuştur.

Kadın giyimindeki değişim sadece biçimsel olarak değil, malzeme, süsleme ve aksesuarlarda da görülmüş, Avrupa'dan getirilen malzemelerle geleneksel formların bir arada kullanıldığı giysiler oluşturulmuştur. Koç (2009: 86) çalışmasında, uzun yıllar oldukça sade olarak hazırlanan feracelerin biçimlerinin 19. yüzyılda değişime uğradığına, süslemelerinin zenginleştiğine, yakalarının genişlik ve uzunluklarının değiştiğine dikkat çekerek, giyim kuşamdaki katı ve belirlenmiş formların ve kuralların kırıldığını belirtmiştir. "II. Meşrutiyet’ten sonra yaşanılan değişimler hızla devam etmiş, yaşamın her alanında gittikçe yaygınlaşan alafranga anlayış, giyim konusunda da dönemin gazete ve dergilerinden yakından takip edilmeye başlanmıştır" (Koca, 2012:678). Aylık olarak yayınlanan bu dergilerden biri olan ve ilk kez renkli resimlere yer veren kadın dergisi Mehasin, 1906-1907 yılları arasında toplam 12 sayı yayınlanmıştır. Diğer kadın dergilerinde olduğu gibi, Mehasin dergisinin içeriğinde de Batı modasına yönelik sayfalarda, elbise görsellerinin yanı sıra iç giyim, süslenme ve

Turkish Studies, 15(1) 
aksesuarlarla ilgili bilgi ve görsellere de yer verildiği, dönem dergileri ile ilgili çalışmalarda da vurgulanmaktadır. Batıcı akıma mensup Mehasin dergisinin yazar ve düşünürleri yayınlanan sayılarda Batı tarzında kadın modasını ve aksesuarlarını Türk kadınına tanıtmaya çalışmıştır. Taşçıŏlu'nun (1958:28), "batıcılık rüzgârlarının estiği kadın dergilerinde o günün kadın modasını yansıtan kıyafetler ise genellikle etek-bluz şeklinde, belde sıkı bir kemer ile tamamlanmıştır. Bluzlar çok büzgülü olup pililer, danteller ve şeritlerle süslenmiştir" betimlemesi ile kadın dergilerinde yayınlanan Avrupa kadın giyim modasının dergiler aracıllğıyla dönemin Türk kadınını etkilediği desteklenmektedir.

Türk kadınının özgürlük ve modernleşme konusunda başlattığı önemli bir sürecin başlangıcı sayılan II. Meşrutiyet basınında kadın dergileri, modaya yönelik içerikleriyle kadınların giyim tarzlarında değişime yol açarak, Meşrutiyet kadınına yeni bir imaj kazandırmıştır. Bu imajın günümüz Türk kadınının modern giyim tarzının ilk adımlarını oluşturduğu dikkate alındığında, dönem dergilerinde yer alan kadın modasına yönelik görseller ve bilgilerin, Türk kadınının giyim tarzındaki değişimde ne denli önemli olduğunu ortaya koymakta ve bu çalışmanın çıkış noktasını oluşturmaktadır. Bu çalışmada, II. Meşrutiyet döneminde yayınlanan kadın dergilerinden biri olan Mehasin dergisinin 1906-1907 yılları arasında yayınlanan sayılarındaki kadın modasının nitel (tasarım) özelliklerinin belirlenerek, Türk kadınının giyinme kültürünün değişimine yansımalarının yorumlanması amaçlanmıştır. Döneminde yayınlanan diğer kadın dergilerine göre kadın modasına daha fazla yer vermesi nedeniyle, Mehasin dergisi araştırma kapsamına alınarak, dönemin Avrupa kadın modasının genel özellikleri incelenmiş ve açıklanmaya çalışılmıştır. Araştırma, birincil kaynaktan bilgi birikimine katkıda bulunarak, Türk giyim tarihine kaynak oluşturabilmek açısından önem taşımaktadır.

\section{Yöntem}

II. Meşrutiyet dönemi kadın dergilerinden biri olan Mehasin dergisinin 1906-1907 yılları arasında yayınlanan sayılarındaki kadın modasının nitel (tasarım) özelliklerinin belirlenerek, Türk kadınının giyinme kültürünün değişimine etkilerinin yorumlanmasının amaçlandığı bu nitel araştırmada, içerik analizi yöntemi kullanılmıştır.

"İçerik analizinde unsurlar, bir kodlama sistemi ile gerçekleşir. Kodlama, metindeki bilgileri sistematik olarak gözlemleme ve kaydetme biçimleriyle ilgili bir dizi talimat ya da kuraldır" (Neuman 2013: 468). Bu doğrultuda genel bir çerçeve içinde yapılan ancak daha önceden belirlenmiş kavramlar doğrultusunda gruplanan bir kodlama sistemi geliştirilmiştir. Oluşturulan kodlama listesi (Tablo 1) farklı zamanlarda sistematik olarak incelenmiş ve zaman içinde yapılan kodlamaların birbiriyle örtüştüğü görülmüsstür.

Tablo 1:Veri Kod Listesi

Siluet özellikleri

Yaka özellikleri

Kol özellikleri

Süsleme özellikleri

Kumaş/malzeme ve renk özellikleri
Tablo 2: Kodlara Göre Oluşturulan Temalar

Siluet özelliklerine göre çıkan temalar Yaka özelliklerine göre çıkan temalar Kol özelliklerine göre çıkan temalar Süsleme özelliklerine göre çıkan temalar Kumaş ve renk özelliklerine göre çıkan temalar

"Temaların bulunması için, önce kodlar bir araya getirilir ve incelenir. Kodlar arasındaki ortak yönler bulunmaya çalışılır. Bu bir anlamda tematik kodlama işlemidir. Tematik kodlama için ilk aşamada ortaya çıkan kodları bir araya getirebilecek türden temaların belirlenmesi gerekir" (Yıldırım ve Şimşek 2008: 236-237). Bu doğrultuda kodlanan verilerden yola çıkılarak ortak kavramlar bulunup, giysi özelliklerini açıklayabilecek genel temalar oluşturulmuştur (Tablo 2).

Araştırmada, Mehasin dergisinin 1906-1907 yılları arasındayayınlanan12 sayısının modaya yönelik sayfaları belirlenerek, giysi özellikleri tam olarak görülebilen görseller belirlenmiş, 
kronolojik sıralamayla görsellerin tabloları oluşturulmuş ve içerik analizi yöntemi ile derinlemesine incelenmiştir. Benzer olan giysi görsellerinden tüm özellikleri en iyi yansıtan görseller araştırma kapsamına alınmıştır. İnceleme sürecinde tematik kodlama işlemi yapılarak, kodlara göre giysi görsellerinin biçimsel çizimleri yapılmış ve temalar oluşturulmuştur. Araştırmanın amacına ulaşmak için belirlenen kodlar ve oluşturdukları temalar doğrultusunda aşağıdaki sorulara yanıt aranmıştır:

- Mehasin dergisindeki Avrupa modasına yönelik sayfalarda kadın giyiminin siluet, kol ve yaka özellikleri nasıldır?

- Mehasin dergisindeki Avrupa modasına yönelik sayfalarda kadın giyiminin süsleme ve aksesuar özellikleri nasıldır?

- Mehasin dergisindeki Avrupa modasına yönelik sayfalarda kadın giyiminin malzeme/kumaş özellikleri nasıldır?

Sayfalardaki Osmanlıca metinlerin Türkçe çevirisinden elde edilen bilgiler doğrultusunda dönemin Avrupa kadın modasının tasarım özellikleri açıklanmış ve Türk kadının giyinme kültürüne yansımaları yorumlanmıştır. Ayrıca, söz konusu döneme ait Avrupa kadın giyim modasını yansıtan görsellerin kod ve tema şeması oluşturularak söz konusu dönemin kadın giyim modasının çerçevesi çizilmiştir.

\section{Bulgular ve Tartışma}

II. Meşrutiyet dönemi 1906-1907 yılları arasında yayınlanan Mehasin dergisinde yer alan kadın giyim modasının nitel (tasarım) özelliklerini belirlemek amacıyla, kronolojik olarak sıralanan dergi görselleri siluet, kol, yaka, süsleme başlıkları altında tek tek kodlanmış, ortak kodlar bir araya getirilerek genel temaların oluşturulduğu tematik kodlama tabloları aşağıda sunulmuştur. Dergilerdeki görsellerin siyah beyaz olması nedeniyle giysilerin kumaş ve malzeme özellikleri net olarak incelenemediği için, tablolarda bu kod ve temalara yer verilmemiş, ancak, dergideki yazılı metinlerin çevirisinden elde edilen bilgiler doğrultusunda bu temalar, diğer temaların içeriğiyle birlikte yorumlanmıştır.

Derginin kadın giyim modasına yönelik sayfalarında yer alan içerikler her sayıda farklılık göstermekle birlikte, giysi tamamlayıcıları, süslenme ve özellikle saç bakımı hakkında Türk kadınını aydınlatıcı bilgiler içermektedir. Derginin ilk sayısında "Patron Siparişi" başlığı altında, beden üzerinden nasıl ölçü alınacağına ilişkin bilgiler yer almış, bel, kalça, göğüs ölçüleri verilmiş, bluz modelinin bu ölçülere göre biçkisinin ve dikimin nasıl yapılacağı anlatılmıştır. Kadın bluzlarının dışında, çocuk elbise modelleri verilmiş ve patronlarının (kalıplarının) nasıl çıkarılacağı anlatılııştır. Bu dönemde özellikle kız çocuklarının küçük yaşlardan itibaren dikiş dikebilen, kalıp çıkarabilen yetilere sahip olarak yetiştirildiği ilgili kaynaklardan da bilinmektedir. Yapılan incelemede, Mehasin dergisinin ilk sayısından itibaren birçok Avrupai tarzda modelin patronlarına yer verdiği görülmüştür. 
Tablo 3: Mehasin Dergisi 1906 Yılı 1-2-3 Sayılarında Yer Alan Kadın Giysi Görselleri Tematik Kodlama Tablosu

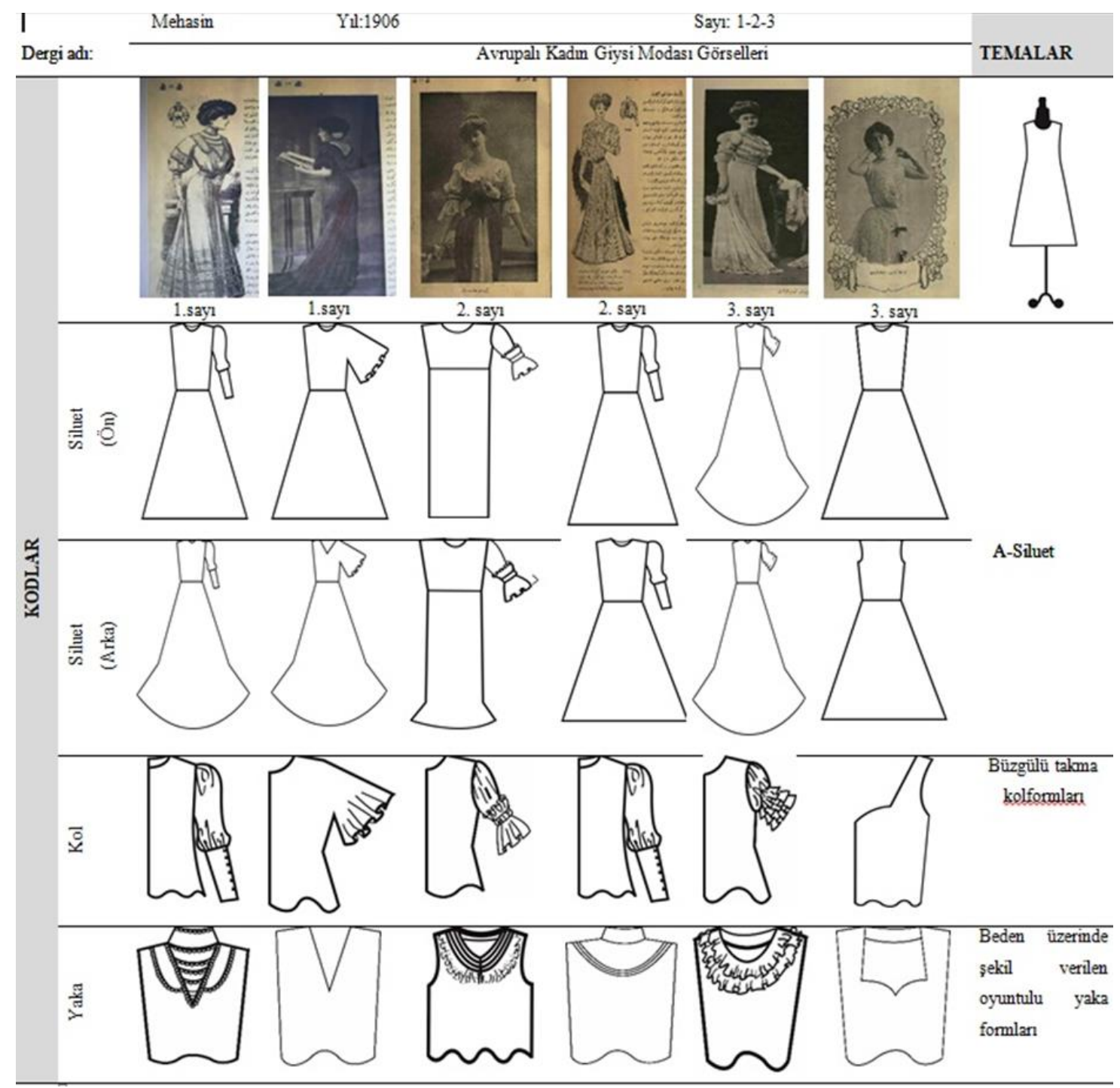

Tablo 3’teki Mehasin dergisinin ilk üç sayısındaki görseller incelendiğinde, Avrupalı kadınların giydiği moda giysilerin sayfalarda yer aldığı görülmektedir. Kodlar ve oluşturdukları temalar çerçevesinde giysilerin tasarım özelliklerinin; beli sıkıca saran, etek uçlarına doğru açılan A siluet formunda oldukları ve belin ince görünümünü veren korselerin iç giyim olarak kullanıldığını söylemek mümkündür. Şeni ve Quataert (1990: 58, 2009: 224), yeni moda giyim tarzlarını benimsemeye başlayan şehirli seçkin kadınların ince belli görünmek için korse takmaya başladıklarını, saçlarını topuz yaptıklarını ve bu yeni giysileri vücutlarının her yerini örten çarşafların altına giyinerek kamusal alandan sakladıklarını belirtmeleri, Tablo 3 'teki korseli giysi görünümünü ve dönem kadınlarının korse kullandığını doğrular niteliktedir. Ayrıca, bu uzun çarşaf batılı biçime dönüştükçe, peçe kullanımı azaldıkça, kendisi gibi giyinmeyeni küçük gören, cüretkâr modern şehirli kadın tipinin ortaya çıktığını vurgulamaları, Osmanlı kadınının Avrupa modasını kolay benimsediği ve bu dönemde kadınların korse kullanımının yaygınlaştığı izlenimini yaratmaktadır. 
Giysilerin A siluet formlarının "koyun budu kol” formu olarak bilinen, dirseğe kadar kabarık, dirsekten bileğe kadar kolu sıkıca saran uzun kollarla bütünlügünün sağlandığı, kısa kolların ise volan ya da firfır detayları ile çeşitlilik kazandığı görülmektedir. Dönemin yaka çeşitlerinin genellikle beden üzerinde şekillendirilmiş V ile sıfır yaka formunda olmasına rağmen, bedene takılan dik yaka formunun da kullanıldığını söylemek mümkündür. Süsleme detaylarında ise genellikle kalıp ve dikiş teknikleri ile çalışılmış, volan, firfir ya da pilliler en çok görülen süsleme teknikleridir. Koca ve Emiroğlu (2019:249), 1900 yılında kadın giysilerinde uzun bir aradan sonra koyun budu kolların yeniden gündeme geldiğini belirterek, yoğun büzgü ve drapelerle göz dolduran kolların, dantel, firfır ve içine konan vatka ve yastık gibi desteklerle yüzyı1lık dönemin en abartılı görünümüne kavuştuklarına ve görsellikte giysi siluetlerinin önüne geçtiklerine dikkat çekmişlerdir. Taşçığlu'nun (1958: 28), dönem giysilerinin çok büzgülü olup pililer, danteller ve şeritlerle süslendiğini, kolların ise genellikle uzun, yakaların da zamanın modasına göre dik olduğunu belirtmesi, Tablo 3 'teki görsellerin tasarım özelliklerini doğrular niteliktedir.

Derginin ikinci sayısındaki, "giysilere güzellik veren dikiş ve el işleridir. Asabi parmakların hâkimiyeti sanat karisi altında seri hamleliklerle beyaz bir kumaşın kenarlarını bastıran yahut onun yanına bir numune- i sanat nakış eden parlak iğneler..." konulu yazıda İngiliz kadınlarının bluz veya gömleklerindeki süslemelerin zariflikleri anlatılmıştır. Osmanlı kadınlarının dönemin modasından geri kalmamasını sürekli dile getiren Mehasin dergisinin bu sayısında da yine Avrupa modasında kullanılan el işçiliğine vurgu yapılmıştır. Ayrıca kadınlar için dikiş işleriyle uğraştıklarında ne kadar güzel ve ne kadar tebcil olurlar ifadeleri kullanılmıştır. Derginin ilk iki sayısında Avrupalı kadın giyiminin kadınlara sağladığı estetik görünüm yansıtılmış, giysilerde kullanılan dantel yaka süslemelerine özel yer verilmiş ve o dönem moda olan kolye, bileklik, toka gibi görsellerin Fransızlara ait olduğu belirtilmiştir.

Derginin ikinci sayısında saç bakımına ilişkin bilgiler de yer almıştır. Hüseyin Naim'in "Yeni Saçlar" yazısında; kadın dergilerindeki bu moda furyasından sadece kıyafetler değil kadın güzelliğini tamamlayan diğer unsurların da payını aldığı, bol, ince, uzun ve parlak saçların bir kadının yüzündeki güzelliğin en önemli göstergesi olduğu vurgulanarak, saç bakımının öneminden bahsedilmiştir. Bakılmayan saçların zamanla dökülmesinden dolayı Avrupa'da kadınların takma saça rağbet ettiği, Osmanlı kadınlarının da takma saç modasına uydukları, bunları ya Avrupa'dan bizzat getirdikleri veya Beyoğlu'ndaki saçcılardan aldıkları belirtilerek, kadınlardaki beğenilme arzusunun sonu olmayan iradesiz bir ihtiyaç olduğuna dikkat çekilmiştir (Mehasin,1324: 73-76). Pardoe (1999: 12) ise seyahat anılarında bu durumu; "çoğu kadın azalan saçlarından dolayı, takma örgüleri kullanmak durumunda kalıyor. Bunları da fazlasıyla abartılı takarlar, takma saçı gayet çirkin biçimde sardıkları işlemeli yemenilerin kıvrımlarına doluyor ve mücevherlerden olan elmas veya zümrüt tokalarla tutturuyorlar" ifadeleriyle anlatmıştır. Derginin içeriğinin çok geniş olduğu, kadınların sadece modaya dair değil, saç, güzellik ve bakım gibi birçok konuda bilgilenmesini amaçladığı, hatta Avrupa kadınlarının kullandığı peruk, takma saç ve saç bakım ilaçlarına dâhi değinildiği görülmüştür.

Derginin üçüncü sayısında yayınlanan görsellerin diğer iki sayıdakilerden farklılıkları arka etek uçlarının yere sürünen kuyrukları ve yaka formlarındaki derin dekolte görünümleridir. Süsleme olarak yakalarda volan veya firfir detayları kullanılırken, bedende kurdeleler ve dikiş tekniklerinin süsleme unsuru olarak kullanılması dikkat çekmektedir. Giysilerde kadife, ipek ve keten kumaşların kullanıldığı, renk olarak ise kahverengi ve kırmızı tonlarından bahsedildiği dergideki bilgiler arasında yer almaktadır.

Dergideki bilgilerden, giysilerde genellikle dökümlü ve ipek kumaşların kullanıldığı, desenli kumaşlara çok fazla yer verilmediğini söylemek mümkündür. Özellikle derginin üçüncü sayısında kumaş özelliklerine ilişkin bilgilere yer verilmiş, kahverengi kadife kumaşlardan, ipeklerden ve dantellerden elbiseler dikildiğinden bahsedilmiştir. Saz (1974: 89), saraydaki kahveci ustanın 
giydiği giysiyi şu şekilde tanımlamıştır; "ustabaşı, arkasında iki örgü saçı, entarisinin üstünde ipekli kumaş üzerine etrafina sırma ile işlenmiş hırka giymiştir. Sanırım bu hırka zamanın modasına karşı icat edilmiştir". Saz'ın ipek kumaşların saray giyiminde önemli yeri olduğunu, sarayda kalfaların bile ipek kumaşlar giydiğini belirtmesi, Osmanlı kadını için ipek kumaşın Avrupai giysi formları gibi bir yenilik olmadığı şeklinde yorumlanabilir. Üçüncü sayıda ayrıca Avrupa dantellerinin kullanılmasını teşvik etmek için; "her ne kadar makinede yapılan danteller el ile yapılanlar kadar kıymetli değil ise de dikkatle yapılanları hakikilerinden güçlükle tefrik edilmekte ve arz edilmektedir" ifadesi kullanılmıştır. Derginin üçüncü sayısının beşinci sayfasında ise ilk defa Osmanlı kadını için mayo sözcüğü kullanılmış; "bu cambaz kiz dizelerinde ve kollarında ten rengi mayonun yanında, kırmızı kadifeden dar elbiseyle pek atif ve nazarrüba ortaya çıkmıştır" betimlemesiyle, kadınların Avrupai giyim modasına ilgileri vurgulanmıştır.

Mehasin dergisinin dördüncü sayısının bilgi içeren sayfalarında, ölçülere göre nasıl elbise patronu (kalıp) çıkarılabileceğine yer verilerek, Avrupa'da en moda olan giysileri kendilerinin dikebilecekleri yönünde kadınların teşvik edildiği anlaşılmaktadır. Osmanlının gelir düzeyi yüksek mevki sahibi kişilerinin eşlerinin genellikle giysilerini terzilere diktirdikleri düşünüldüğünde, Avrupa modasını takip etmek isteyen şehirli kadınların bu dergilerin kalıp ve dikim ile ilgili bölümlerinden faydalandıkları söylenebilir. Karakışla'nın (2014:81), her nevi kostüm, tayyörler, çarşaflar, bluzlar, mantolar, yeldirmeler, maşlahlar, roblar, eteklikler, cihaz (çeyiz) takımları ve çocuk elbiseleri içeren dergilerin İstanbul Hanımlar Terzihanesine kadınlar tarafından Avrupa'dan özel olarak her hafta muntazaman getirildiğini belirtmesi, model ağırlıkı bu dergilerin kadınlar için ne kadar önemli olduğunu göstermektedir. Bu nedenle, dönem kadınlarının giyim modasını Avrupa'dan getirilen modellerden takip ettiğini ve giysilerin terziler tarafından bizzat patronları çıkarılıp dikildiğini söylemek mümkündür. Derginin beşinci sayısında da dikiş ve kalıp bilgilerine yer verildiği görülmüştür. Ölçülerin nasıl alınması gerektiği detaylı olarak okuyucuya anlatılmış, kol boyu, etek boyu, beden genişlik ölçüleri tek tek belirtilerek kalıbın nasıl hazırlanacağı konusunda bilgilere ulaşılmıştır.

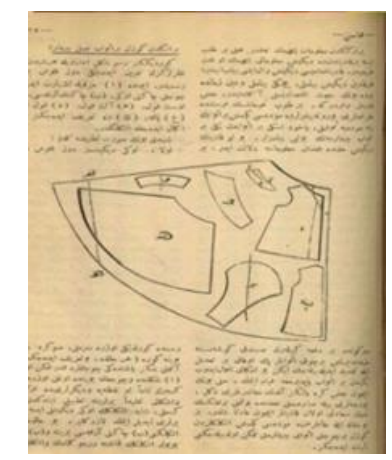

Resim 1: Giysi Kalıp ve Açıklamaları (Mehasin Dergisi, 1906: 267)

Resim 1'deki giysi kalıbı incelendiğinde, A siluet formunda belden kesikli, prenses yakalı (omuzları açıkta bırakacak şekilde bir bandın kol ve bedene takılmasıyla oluşturulmuş yaka formu) ve üst kısmı oldukça büzgülü bileğe doğru daralan kollu bir elbise olduğu açıkça görülebilmektedir. $\mathrm{Bu}$ kol çeşidi, dönemin kadın giysilerinde sıklıkla kullanılan koyun budu kol formudur. Dergide verilen giysi patronu hakkındaki açıklama şöyledir: "7 büyüklükte 75 santimden, 110 santime kadar gögüs ölçüsüyle, 5 büyüklükte ve 75 santimden, 105 santime kadar gögüs ölçüsüyle, genç kizlara mahsus prenses usulünde elbise; 14 yaşından 19 yaşına kadardır" (Mehasin, 1906: 267). Metinden de anlaşıldığı gibi okuyucuya anlatılan giysinin, farklı vücut ölçülerine sahip genç kızlara yönelik, adını yakasının formundan alan elbise kalıbı olduğunu söylemek mümkündür. $\mathrm{Bu}$ durum, II. Meşrutiyet döneminde sadece kadınların değil genç kızların da Avrupai giyim tarzlarına 
yönlendirildiği ve genç kızlarında kendi elbise kalıplarını hazırlayarak giysilerini dikmeye teşvik edildiğini göstermektedir.

Tablo 4: Mehasin Dergisi 1906 Yı1ı 4-5-6 Sayılarında Yer Alan Kadın Giysi Görselleri Tematik Kodlama Tablosu

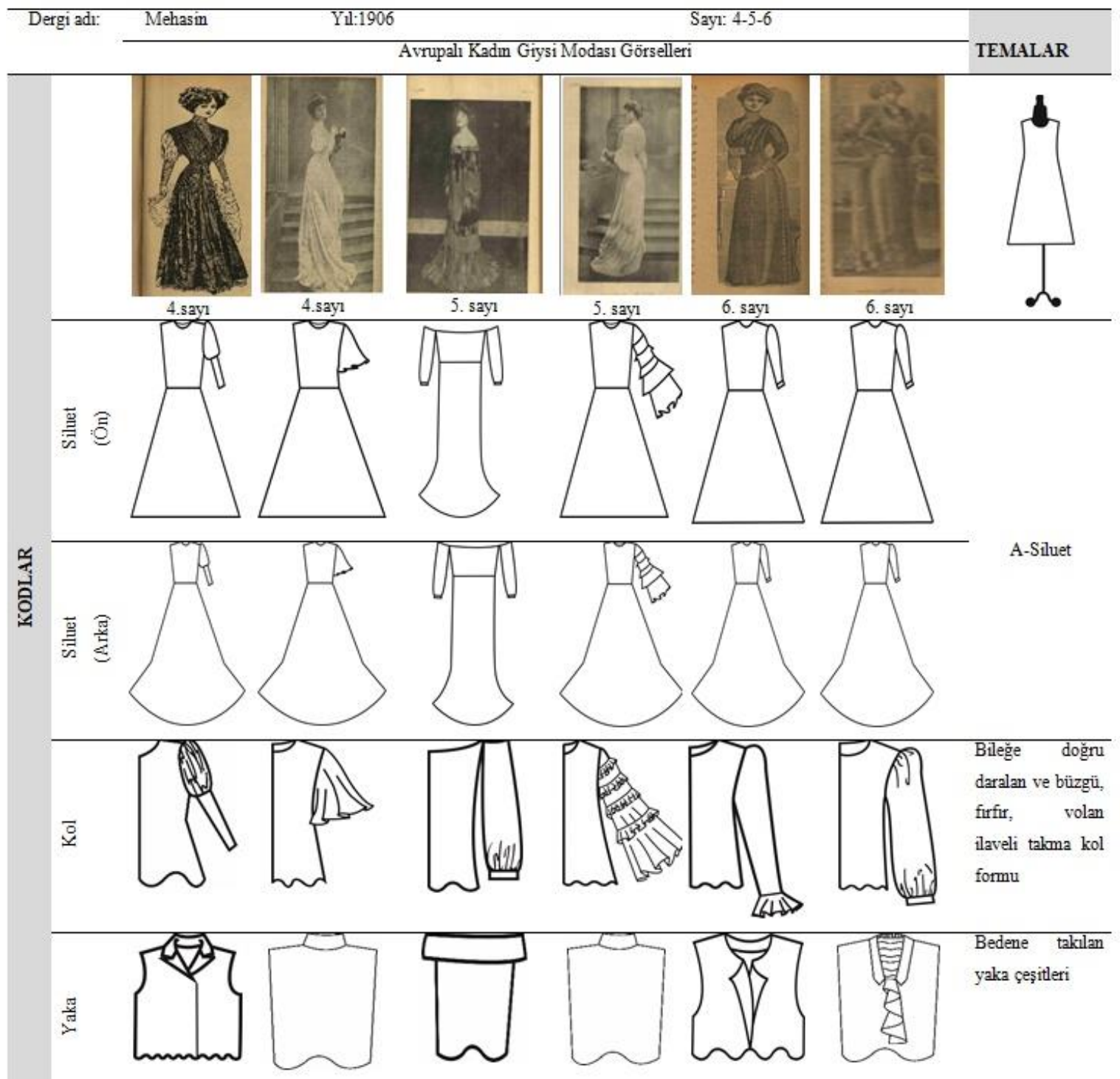

Tablo 4'te derginin üç sayısındaki $(4,5,6)$ giysiler kodlara göre incelendiğinde, önceki sayılardaki giysilerin özellikleriyle benzerlikler olduğu görülmektedir. Siluet açısından A siluet formunun egemenliğini sürdürdüğü, ancak eteklerdeki uzun kuyrukların yaygınlaştı̆̆ı, koyun budu kolun yerini bol, büzgülü, firfirlı ve volanlı kolların yanı sıra bileğe doğru daralan uzun kollara bıraktığ1 söylenebilir. Koca ve Emiroğlu'nun (2018: 250), 19. yüzy1lın sonlarında Avrupa modasında, düz siluetin yerini bel hattını sıkıca saran korsajlı kabarık etekleri ve kıvrımlardan oluşan kabarık uzun kollarıyla A siluet formunda görkemli giysilerin aldığını belirtmeleri, Tablo 4'teki görsellerin kodlarına yönelik tespitleri desteklemektedir.

Yaka formları incelendiğinde ise bedene takılan yaka çeşitlerinden dik yakanın derginin bu sayısındaki giysi görsellerinde de görüldüğü, röverli yaka çeşitlerinin ve beden üzerinde şekil verilmiş yaka oyuntularının çevresine farklı biçimlerde yakalar takıldığ 1 gözlenmektedir. Ayrıca 
omuzları açıkta bırakan ve prenses yaka olarak adlandırılan yaka formuna bu sayıda ilk kez rastlanmıştır. Osmanlı toplumunda sosyal yaşam içinde kadının konumunun belirli sınırları olduğu ve Avrupai giyim tarzlarının yoğun şekilde eleştirildiği düşünüldüğünde, bu yaka biçiminin, kadın dergilerinde kalıpları verilerek sunulması dikkat çekici bulunmaktadır. Giysilerde süsleme detayları olarak kalıp ve dikiş teknikleri ile oluşturulan büzgü, firfir, pili ve volan kullanılmış, işlemeler ve kurdeleler ile de süslemeler yapılmıştır. Özellikle bluzların yakalarında volanlar ya da pililer süsleme olarak kullanılmıştır.

Derginin beşinci sayısında giysilerle kullanılan değerli takılar ve elmaslarla ilgili bilgiler de moda sayfalarını tamamlayan konulardır. Bu sayıda, iç giyim modellerin görsellerine de yer verilmiş olup, korseler, iç etekler ve gecelikler tanıtılmıștır. Bu dönemde Avrupalı kadınların giysilerin altına bellerini ince göstermek için korse ve giysilerin daha hacimli görünmesi için kat kat jüponlar giydikleri anlatılmış, fırfırlı, büzgülü, kabarık iç etekler ve çeşitli korse görselleri ile Osmanlı kadınının dikkatine sunulmuştur.
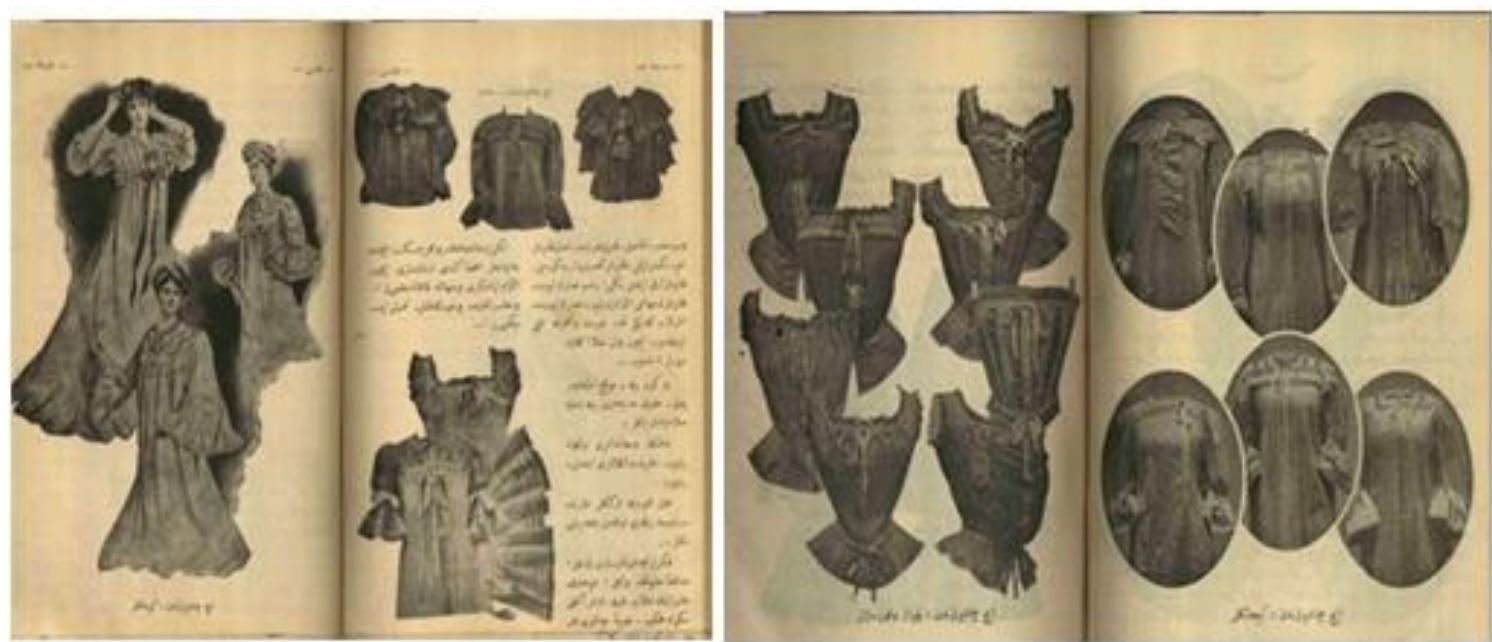

Resim 2: İç Giyim Görselleri (Mehasin Dergisi, 1906: 147)

Mehasin dergisinin 1906 yılında çıkan altıncı sayısında modaya ilişkin işleme ve süsleme örnekleri yer almış, mendil kenarlarına yapılan, "kenar lalesi" dikişi ifadesi kullanılmıştır. Keten, ipek ve kareli kumaş üzerine yapılan çiçekli süslemelerin iğneyle nasıl işlendiği ve ipek kurdele ile süslendiği anlatılmıştır. 
Tablo 5: Mehasin Dergisi 1907 Y1lı7-12 Sayılarında Yer Alan Kadın Giysi Görselleri Tematik Kodlama Tablosu

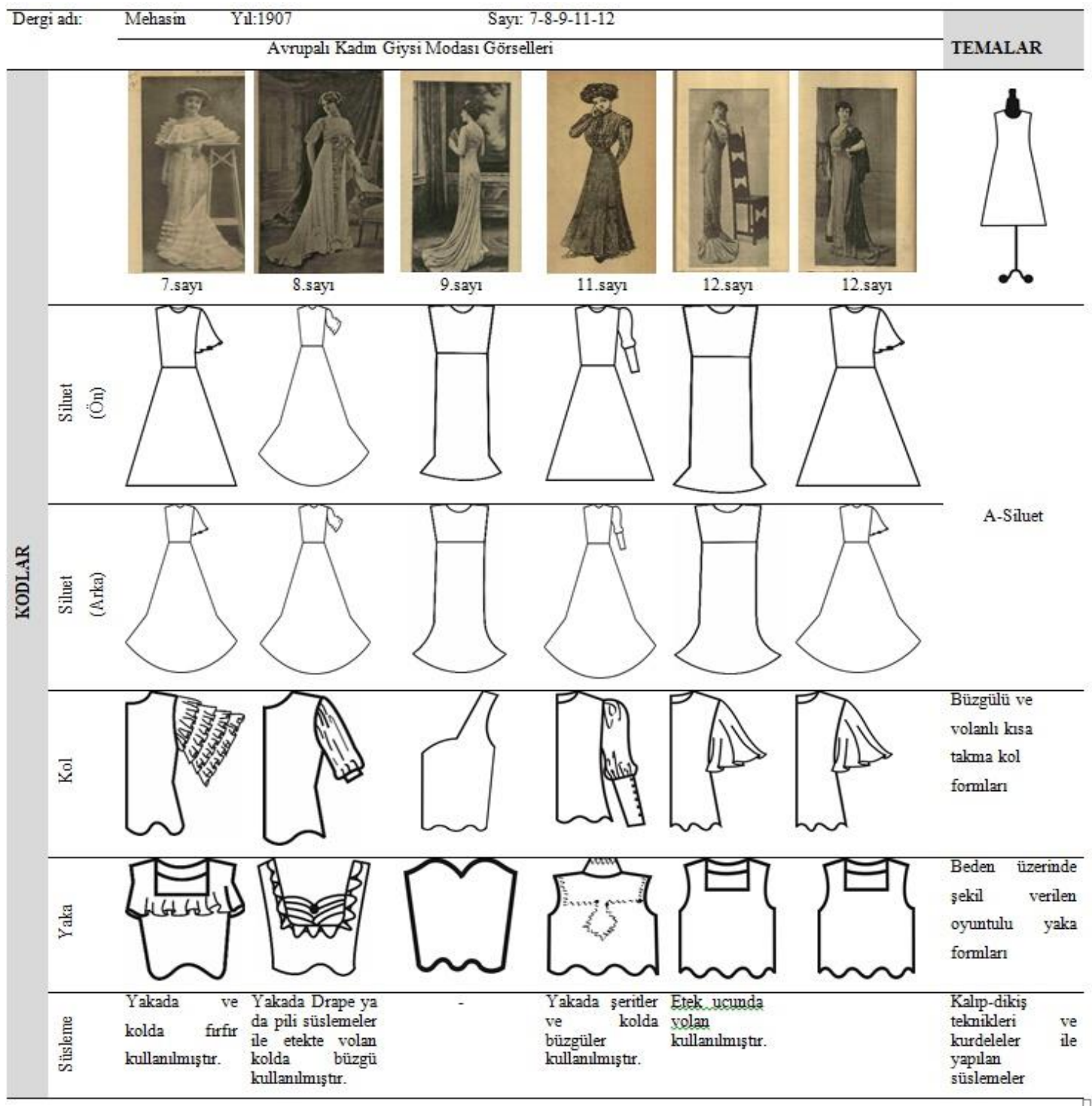

Tablo 5'teki dergi sayılarında yer alan görsellerin, kodlar ve oluşturdukları temalar açısından diğer sayılara göre değişim gösterdiği görülebilmektedir. Giysilerde A siluetin ve kuyruklu eteklerin yanı sıra $\mathrm{H}$ suliet formu dikkat çekmektedir. Özellikle on ikinci sayıda giysilerin tümü ampir kesimli $\mathrm{H}$ siluet formundadır. Kollar ise genellikle kısa boyları ile değişim göstermekte, ancak volan ve büzgü gibi özellikler Tablo 3 ve 4'teki kolların detaylarıla benzemektedir. Yaka formlarında ise beden üzerinde şekillendirilmiş derin yaka biçimleri görülmektedir. Kare yaka formunun en yaygın kullanılan yaka çeşidi olduğu söylenebilir. Tüm giysilerde süsleme malzemesi olarak genellikle kurdele kullanılırken, firfir ve volan ise tercih edilen süsleme teknikleri olarak kullanılmaya devam etmiştir. Dergide yer alan bilgiler de giysilerde ipek ve keten kumaş kullanıldığı belirtilmiştir. Sevin (1990: 140), II. Meşrutiyet döneminde Avrupa moda akımının Osmanlı kadınlarını etkilediğini belirterek, giysilerde daralmalar olduğu ve bazen yanlara, bazen arkaya kuyruk gibi kumaşlar, sayısız düğmelerle iliştirilerek hacim kazandırıldığından bahsetmesi, giysilerdeki suliet değişimine işaret etmektedir. 
Derginin 1907 yılında yayınlanan yedinci sayısında gecelik ve iç giyim ile ilgili modeller ile bu modellere ait patronlar verilmiş ve biçkisinin nasıl yapılacağı okuyucuya detaylı olarak anlatılmıştır. Ayrıca, dönemin kumaş türlerinden bahsedilmiş, keten ve ipek kumaşların giysilerde en çok kullanılan kumaş çeşidi olduğu gözlenmiştir. Giysi tamamlayıcılarına da yer verilen sayıda şapka ve şemsiyelerle ilgili bilgiler sunulmuştur. Giysilerdeki işlemelerin renginden tekniğine kadar detaylı açıklamalarda bulunulmuştur. İşlemelerle ilgili sayfada; "çar çuhi açık kahverengi kumaş üzerine keza şehrinin ... rengi ipek ile işlenecektir. İşleme keman düz sarma ... keman (kurdele) iğnesi ile olacaktır" şeklindeki tanımlaması, giysileri dikecek kişilere yol gösteren açıklamalardan biridir. Bunun dişında, dönem giysilerini tamamlayan unsurlardan biri olan şemsiyeye de yer verilmiş, beyaz renkli keten kumaş kullanılacağı belirtilerek şemsiyenin kumaş ve renk bilgileri açılanmıştır. Derginin tüm sayılarındaki giysi görsellerinde kullanılması nedeniyle kurdelenin dönem giysilerinde kullanılan önemli süsleme malzemelerinden biri olduğunu söylemek mümkündür.

Mehasin dergisinin sekizinci sayısında genellikle Fransız modası ve Fransız kadınların giyim özellikleri anlatılmış ve kadınlar için iç giyimin önemi vurgulanmıştır. Korse, içe etek ve gecelik gibi iç giyim görselleri incelendiğinde, geceliklerin bol kesimli çok büzgülü kollar ile yakaları firfirlı, volanlı ve kurdele ile süslenmiş oldukları, iç eteklerde ise büzgü ve kat kat firfir kullanıldığı görülmüştür. İç çamaşırlar ve gecelikler başlığı altında şu bilgilere yer verilmiştir: "Şüphe yoktur ki hiçbir şey bir kadını iç çamaşırları kadar mükemmel olarak göstermez... kumaşların latif birer gamze-i ibtisamı gibi görünen latif ve rengarenk kurdelelerle şenlenmiş gecelikler ve korseler vücuda şekil verince mest eden ve şeklinden belli olan alengdarlamal iç etekleri." (Mehasin, 1907: 99-100). Avrupai giyim modasının kadın görünümünde yarattığı zarafetin güzel cümlelerle anlatılması, kadınların bu giyim tarzını benimsemelerini sağlamaya yönelik açıklamalardan biridir. "Yeşil şemsiyelerin koyu lal eldivenler içinde çocuklar tutan ince eller, bir korsenin sevdasında vücut gibi...canlı ve siyah saçlar arkasında... eteklerin şuhu bedenleriyle... kadınların bütün güzellikleri..." (Mehasin, 1907: 99-100) Bu anlatımda da görüldüğü gibi Avrupalı kadının nasıl giyindiği, saçlarının nasıl olduğu ve hangi aksesuarları kullandığının ayrıntılı olarak betimlenmesi, kadınların bu güzellikler karşısında duyarsız kalamayacağı ve kendileri için yeni olan bu güzel tarzı uygulamak isteyecekleri anlamını taşımaktadır.

Moda ürünlerin toplumdaki bireyler tarafından anlaşılır ve yorumlanabilir özelliği, tüketicilerin giysi satın alma davranışlarına yön veren en etkin faktörler arasında olduğu düşünüldüğünde (Koca ve Koç 2016:235); söz konusu dönemde hızlı ve radikal bir değişim olmasa da kadın dergilerinin önemli ölçüde amacına ulaştığı, Osmanlı kadınının giyim tarzlarındaki değişikliklerden anlaşılmaktadır. Tezcan'ın (1988: 45), tarihi süreç içinde kadın giyimindeki değişimin geleneksel, geleneksel ve Batı etkili ve tümüyle Batı tarzında olmak üzere, üç evreden geçtiğini belirtmesi de bu değişimin geçiş dönemlerinin olduğunu ortaya koymaktadır. Derginin dokuzuncu sayısında giysilerin sunumu için canlı mankenlerin kullanıldığ 1 ve bunların "moda kuklaları" olarak isimlendirildiği, bu mankenlerin giydikleri güzel giysilerini gün boyunca terziye gelen kişilere sergiledikleri belirtilmiştir. Derginin ilgili sayfalarında moda kuklalarının giydiği giysilerin görsellerine de yer verilmiştir. Kadınların moda giysiler ile birlikte ellerinde yelpaze ve açık omuzlarını kapatacak şekilde şallar kullandıkları da görseller ve açıklamalarından anlaşılmaktadır. Dergide balo ve gece elbiseleri için kişiye özel dikim yapan terzi reklamları da yer almıştır.

Derginin onuncu sayısında giysi tamamlayıcı ve aksesuarlarına ilişkin bilgilerin yanı sıra çanta, şemsiye, kravat (kadınların taktığı), dantel yakalar, işlemeli mendiller, eldiven, kurdele, gözlük ve broş gibi görseller de bulunmaktadır. Saç bakımına özel bir önem verilmiş, kadınların kullandıkları peruklardan bahsedilmiş, tarak ve tokaların görselleri sunulmuştur. Derginin yayınlanmış olan sayıları içinde hiç bahsedilmeyen, Osmanlı geleneksel kadın giyimine yönelik bilgi ve görsellere bu sayıda yer verilmesi dikkat çekici bulunmuştur. İlgili sayfada geleneksel kadın 
giyimi kullanım alanına göre sokak ve ev giysileri olarak, mevsime göre ise bahar ve kış ayında giyilmek üzere gruplandırılmış ve sokakta giyilen çarşaf ve ferace görsellerine yer verilmiştir.

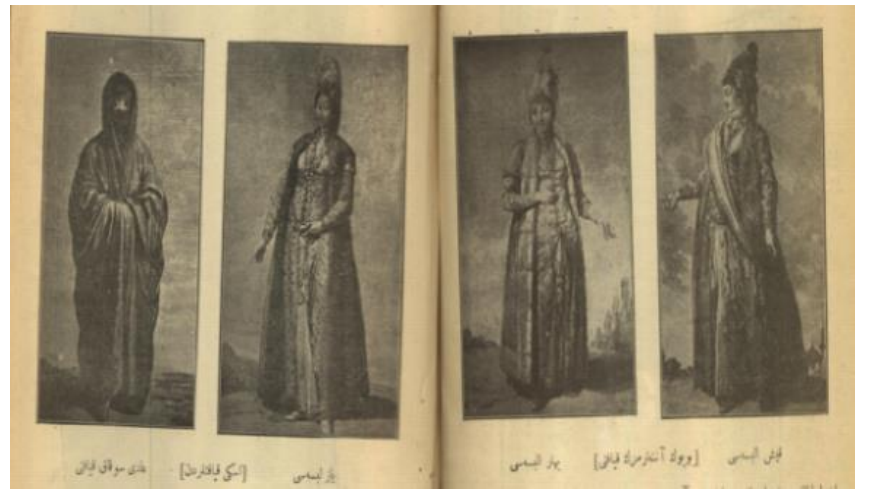

Resim 3: Osmanlı Geleneksel Giyimli Kadın Görselleri (Mehasin dergisi, 1907)

Resim 3’teki görseller incelendiğinde, Mehasin dergisinin tüm sayılarında Avrupa modas1 giysi görselleri ve onları dikmeye teşvik eden bilgiler ve kalıpları sunulmasına rağmen, bu sayıda ilk defa Osmanlı kadınının geleneksel giyimi ile yansıtılmış olması düşündürücüdür. Bu durumda, Osmanlı kadınının Avrupa modasına yönelerek geleneksel giysilerini terk etmesinde, kadın dergilerinin sorumlu olduğuna yönelik eleştirilerin etkili olduğu düşünülmektedir. Derginin on birinci ve on ikinci sayılarında modaya ilişkin bilgiler olmamasına rağmen, Avrupalı kadın görsellerine yer verilmeye devam edildiği gözlenmiştir. Mehasin dergisinin araştırma kapsamındaki 1906 ve 1907 yılında yayınlanan tüm sayılarının modaya yönelik sayfalarından, moda giysileriyle Avrupalı kadın imajının sunulduğu ve kadınların modayı takip etme ve uygulamalarını teşvik edici yayınlar yapıldığını söylemek mümkündür. Kadınlar açısından özgürlüklerin yolunu açan bir dönem olarak bilinen II. Meşrutiyet döneminde, dergiler kanalıyla Avrupa modasını takip etmek kolaylaşmış, dergilerdeki patronları kullanan terziler bu giysileri dikerek modanın yaygınlaşmasına öncülük etmişlerdir. Ancak, geleneksel biçimlerden kopmak çok kolay olmamış, özellikle İstanbul'un önde gelen ailelerinin kadınları giyimlerinden, saçlarına taktıkları aksesuarlara, kullandıkları kumaşlara kadar her şeyde hem doğu hem de Avrupa esintisini harmanlamayı başarmıştır. Bu durum pek çok yabancı gezginin dikkatini çekmiş ve anılarına yansımıştır.

Pardoe (1999:196), İstanbul'da kaldığı yerlerde gördüklerini anlattığ1 seyahatnamesinde Esma hanımın gözdesi Nazife Hanım'ın giyimini şu şekilde tasvir etmiştir; kıyafeti garip bir Avrupa ve doğu karışımıydı. Sarı çiçekli uçuk mavi keten şalvar, pembe ham ipek biyeleri olan açık yeşil entari giymişti. $\mathrm{Bu}$ arada Parisli modacının elinden çıkmış bordo-kahverengi satenden kalın kapitoneli yeleğini çok geniş yenlerinde elmas kol düğmeleri tamamlıyordu. Leyla Saz $(1978: 219)$ ise Osmanlı kadınının giyim tarzındaki değişimini; "20. yüzyılda Avrupa kumaşları giyilmeye başlanmıştı. Kısa etekli etrafi ve kolları kırmalarla, harçlarla süslü göğsü az açık beden modası çıkmıştı. Omuzlardan kesilip ve arka ortasından aşağ doğru bir dikişle endamı gösterirdi. Bele kemer ya da kurdele takmak moda olmuş, şalvar devam etmişti" ifadeleriyle anlatmıştır. Bu betimlemeler, Osmanlı kadınının Avrupa modasına uymaya çalışırken, bir yandan da kendi kimliğini yansıtan geleneksel şalvarından ve yemenisinden vazgeçememesi; her ne kadar Avrupa modasını benimsemeye hazırmış gibi modaya ilgi gösterse de giyim tarzındaki bu radikal değişimi kendi bakış açısıyla yumuşatmayı başardığı anlamını taşımaktadır. Ancak yumuşak bir geçiş olsa da 19. yüzyılın sonlarında kadınlar tarafından benimsenmesi yaygınlaşan Avrupa modasının, İstanbul' da başlayan yolculuğunun, 20. Yüzyılın başlarında daha da hızlanarak diğer illere yayıldığı söylenebilir. Tezcan'ın (1988: 45), geleneksel kadın kıyafetlerinin 19. Yüzyılın ikinci yarısından itibaren Batılı giyim-kuşam tarzının etkilerine açıldığı, yüzyılın son çeyreğinde ise neredeyse tümüyle Avrupalılaştığını belirterek, o yıllarda, kadın giyim kuşamının henüz geleneksel özelliklerini koruduğu, yalnızca bazı aksesuarların Avrupalılaştı̆̆ını vurgulaması bu söylemi desteklemektedir. 
Alp'in (1999:18), 1908- 1923 tarihleri arasındaki kadın giysilerinin, gösterişli takılar ve daha çok eldivenlerle tamamlanmış iki parçaya bölünmüş çarşaf, şapka görüntüsündeki türban ve topuz yapılmış saçlarla bütünleştiğini belirtmesi de Avrupa modasının Türk kadınları tarafından benimsenmesinin hız kesmeden devam ettiği yorumlarını destekler niteliktedir.

\section{Sonuç ve Öneriler}

Mehasin dergisinin 1906-1907 yılları arasında yayınlanan sayılarındaki kadın modasının nitel (tasarım) özelliklerinin belirlenerek, Türk kadınının giyinme kültürünün değişimine etkilerinin yorumlanmasının amaçlandığı bu araştırmada; derginin kadın giyimine yönelik sayfalarında genellikle Fransız modasının ağırlıklı olduğu belirlenmiş, giysi görsellerinin incelenmesi sonucunda dönemin kadın giysi modasının kodları ve kodların oluşturduğu temalar şematik olarak aşağıda sunulmuştur.

Şema 1:1906-1907 yılları Mehasin Dergilerindeki Avrupa Kadın Giyim Modasının Kodları ve Oluşturdukları Temalar

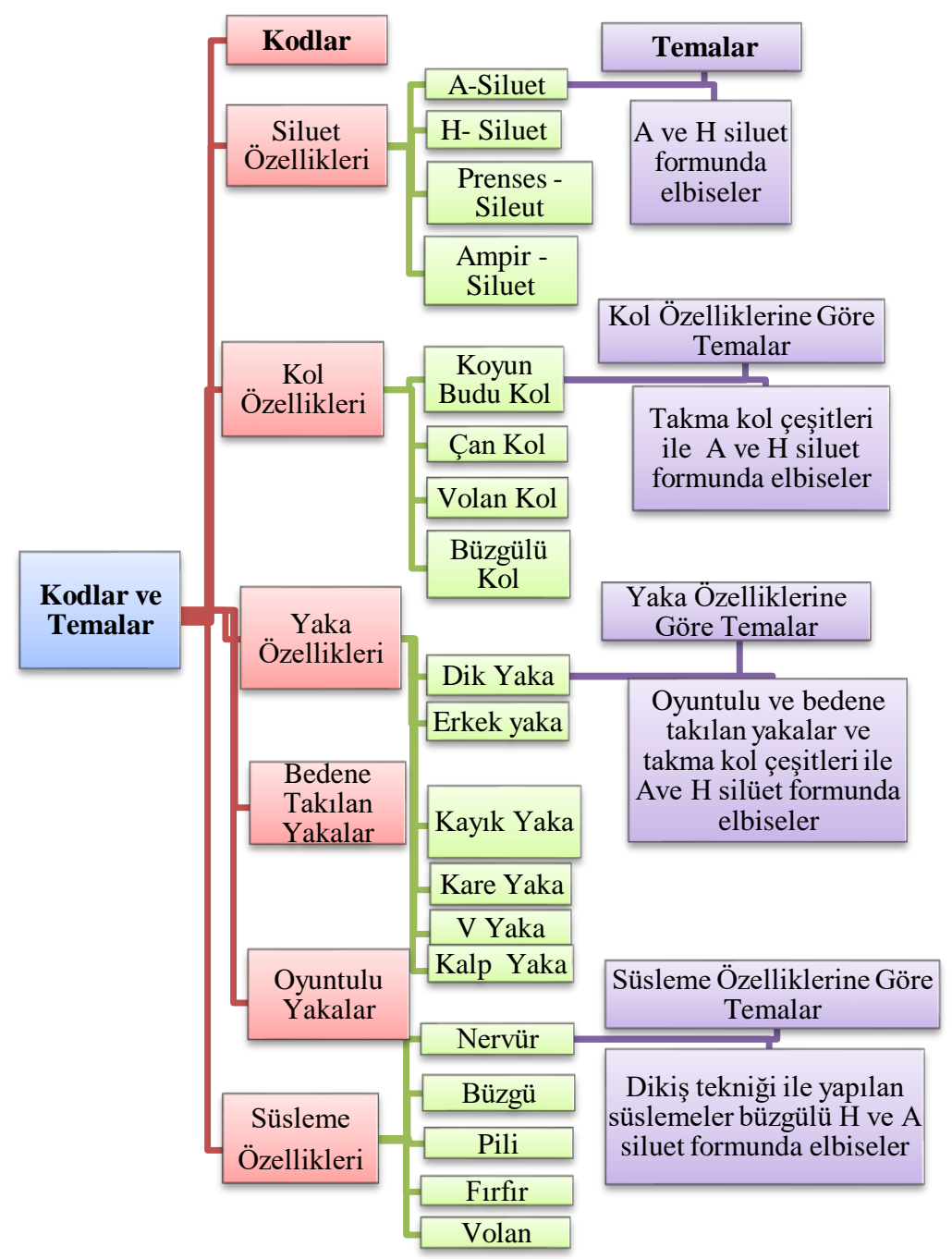

Şema 1 incelendiğinde süliet, kol, yaka ve süsleme özellikleri olarak belirlenen giysi kodlarının, temaları oluşturduğu ve tanımlanan temaların Avrupa kadın giysi modasına özgü formları yansıttıkları açıkça görülebilmektedir. Kodların değişimine paralel olarak değişen temaların yarattığı görsellik Türk kadınını fazlasıyla cezbederek, gelenekselleşmiş olan giyim kalıplarının dışına 
çıkmasının yolunu açmıştır. Bir yıllık periyodda yayınlanan 12 sayısının tümünde moda giyim tarzı ile Avrupalı kadın imajını yansıtarak bu tarzı tamamlayan kalıp, dikiş, süsleme ve saç-güzellik konularına hemen hemen aynı oranda yer veren Mehasin dergisinin Türk kadınının uzun yıllar aynı olan geleneksel giyinme biçiminin değişim sürecinde önemli rolü olduğunu söylemek mümkündür. $\mathrm{Bu}$ bağlamda, Türk kadınının giyim tarzındaki değişim sürecinde etkili olan diğer dergilerin dönemsel olarak ele alınıp araştırılması giyinme kültürümüz açısından önemli görülmekte ve önerilmektedir.

\section{Kaynakça}

Alp, S.(1999). "II. Meşrutiyet Döneminde Kadın Sanatçılar ve Kadın Resimleri”.Anadolu Sanat Sürekli Sanat ve Kültür Dergisi, 10: 14- 27.

Akagündüz, Ü.(2013). "Kadın ve Kadınlığa Dair II. Meşrutiyet Dönemi Dergilerinden Yansımalar (1908-1918)". Folklor/Edebiyat Dergisi, (73): 63-80.

Asaf, M.(1324/1908, Eylül). “Muazzez Karielerimize”. Resimli Kitap Dergisi 1: 1-4.

Çakır, S.(1996).Osmanlı Kadın Hareketi. İstanbul: Metis Yayınları.

Karakışla, Yavuz Selim (2014). Osmanlı Hanımları ve Kadın Terzilleri (1869-1923). İstanbul: Akı1 Fikir Yayınları.

Koca, E. (2012). "Osmanlıda Yapılan Kılık Kıyafete İlişkin Reformların Erkek Giysilerinin Biçimsel Özelliklerine Etkileri” CIEPO -20 Comité International des Études Pré-Ottomanes et Ottomanes, Crete, 27 June -1 July,664-681.

Koca, E., Koç, F. (2016). “A Study of Clothing Purchasing Behavior By Gender With RespectTo Fashion And Brand Awareness". European Scientific Journal, 7: 234-248.

Koca, E., Emiroğlu, S. (2018). “19. Yüzyıl Kadın Giysilerinin Kol Formu Açısından İncelenmesi”. Avrasya Sosyal ve Ekonomi Araştırmaları Dergisi (ASEAD) EurasianJournal Of Researches In SocialAndEconomics 3:238-251.

Koç, F. (2009). “18. Yüzyıl Minyatür Sanatında Osmanlı Kadın Modası” Türk İslam Medeniyeti Akademik Araştırmalar Dergisi 7: 82- 98.

Koç, F. Koca, E., Pamuk, B. (2010). “17. ve 18. Yüzyıl Türk Minyatürlerindeki Kadın Giysilerinde Yaka ve Kol Formu Özellikleri”. III. Uluslararası Türkiyat Araştırmaları Sempozyumu. Ankara: Hacettepe Üniversitesi Basımevi. 479-495.

Koç, N. (2012). "Everyday Life İn Turkey Eserinde Mrs. W. M. Ramsay’ın Osmanlı Ülkesindeki Kadınlara Dair İzlenimleri”. History Studies International Journal Of History2: 235-256.

Neuman, W. L. (2012). Toplumsal Araştırma Yöntemleri: Nicel ve Nitel Yaklaşımlar. İstanbul: Yayın Odasi.

OS, Nicolas, V. (2002). "Milli Kıyafet: Osmanlı Kadını ve Kıyafetinin Milliyeti”. Türkler Ansiklopedisi, C. 14. Ankara: Yeni Türkiye Yay. 133-145.

Özen, H. (1994). Tarihsel Süreç Iç̧inde Türk Kadın Gazete ve Dergileri (1868-1990). İstanbul: Graphis Yayınları.

Pardoe, J. (2010). Sultanlar Şehri İstanbul. Çev. M. Banu Büyükkal. İstanbul: Türkiye İş Bankası Kültür Yay.

Saz, L. (1974). Haremin İç Yüzü. Birinci Baskı, İstanbul: Milliyet Yayınları. 
Sevin, N. (1973). On Üç Asırlık Türk Klyafet Tarihine Bir Bakış. İstanbul: Başbakanlık Kültür Müsteşarllğı Kültür Yay.

Şeni, N. (1990). 19. Yüzyıl Sonu İstanbul Basınında Moda ve Kadın Hareketleri Kadın Bakış Açısından 1980'ler Türkiye'sinde Kadın. İstanbul: İletişim Yay.

Taşçıŏlu, M. (1958). Türk Osmanlı Cemiyetinde Kadının Sosyal Durumu ve Kadın Kıyafetleri. Ankara: Kadının Sosyal Hayatını Tetkik Kurumu Yay.

Tezcan, H. (1988). "Osmanlı İmparatorluğunun Son Yüzyılında Kadın Kıyafetlerinde Batılılaşma”. Sanat Dünyamız Dergisi 37: 45- 51.

Yıldırım, A.ve Şimşek, H. (2008). Sosyal Bilimlerde Nitel Araştırma Yöntemleri.Ankara: Seçkin Yay.

Quataert, D. (2009). Osmanlı İmparatorluğu 1700-1922. İstanbul: İletişimYay.

Mehasin Dergisine Ait Tüm Görsel ve Yazılı Bilgiler Milli Kütüphane Arşivinden Temin Edilmiştir. (Erişim Tarihi: 20.02.2018). 